\title{
Using intervention mapping (IM) to develop a self-management programme for employees with a chronic disease in the Netherlands
}

\author{
Sarah I Detaille*1, Joost WJ van der Gulden², Josephine A Engels ${ }^{3}$, Yvonne F Heerkens ${ }^{4}$ and Frank JH van Dijk 5
}

\begin{abstract}
Background: Employees with a chronic disease often encounter problems at work because of their chronic disease. The current paper describes the development of a self-management programme based on the Chronic Disease SelfManagement programme (CDSMP) of Stanford University to help employees with a chronic somatic disease cope with these problems at work. The objective of this article is to present the systematic development and content of this programme.

Methods: The method of intervention mapping (Bartholomew 2006) was used to tailor the original CDSMP for employees with a chronic somatic disease. This paper describes the process of adjusting the CDSMP for this target group. A needs assessment has been carried out by a literature review and qualitative focus groups with employees with a chronic disease and involved health professionals. On the basis of the needs assessment, the relevant determinants of self-management behaviour at work have been identified for the target population and the objectives of the training have been formulated. Furthermore, techniques have been chosen to influence self-management and the determinants of behaviour and a programme plan has been developed.

Results: The intervention was designed to address general personal factors such as lifestyle, disease-related factors (for example coping with the disease) and work-related personal factors (such as self-efficacy at work). The course consists of six sessions of each two and a half hour and intents to increase the self management and empowerment of employees with a chronic somatic disease.

Conclusion: Intervention mapping has been found to be a useful tool for tailoring in a systematic way the original CDSMP for employees with a chronic somatic disease. It might be valuable to use IM for the development or adjusting of interventions in occupational health care.
\end{abstract}

\section{Background}

In 2007, 39 percent of the U.S. working age population had at least one chronic disease such as diabetes, asthma or depression [1]. Prognostic studies predict an increase in the next twenty years of the incidence of chronic diseases like asthma, chronic obstructive pulmonary diseases (COPD), diabetes and rheumatoid arthritis (RA) in the working population $[2,3]$.

Many people with chronic diseases are able to lead productive lives if supported to do so. However, a chronic disease, such as RA or COPD, has a multidimensional

* Correspondence: sarah.detaille@han.nl

1 Seneca, Expertise Centre for Sports, Work and Health, HAN University of Applied Sciences, Nijmegen, The Netherlands

Full list of author information is available at the end of the article impact on peoples' lives, which can result in limitations in performing activities of daily life and at work, and therefore in job loss or permanent work disability [4-8]. In the Netherlands only one third of the people between the ages of 16 to 64 with a chronic disease have a paid job in comparison to two thirds of the general population [4]. Despite improvements in facilities and medical care, thirty percent of the employees who have a chronic disease have problems at the workplace related to the disease $[9,10]$.

In traditional occupational health interventions, the client had a rather passive role. In the past decade, occupational health interventions have also focussed on empowerment and health promotion among employees 
$[11,12]$. In the Netherlands, recent disability pension legislation has made employees themselves more responsible for job retention [13].

In a systematic review Verbeek et al [14] proposed to classify the outcomes of occupational health intervention programmes into three categories: 1) exposure change, 2) skills and behaviour change, and 3) disease and disability change. Most existing occupational health intervention programmes are based on skills and behaviour change and have focused on empowerment at the workplace, like acquiring psychological support, communication skills, training in requesting work accommodations and on feelings of self-confidence or self-efficacy in dealing with work-related problems $[11,15,16]$.

Different studies based on the patient's perspective which have been used in the needs assessment (see method and results section) provide information that employees with a chronic disease need to acquire empowerment skills to cope with the problems encountered at work because of their chronic disease. There is some evidence that occupational health interventions for employees with a chronic disease based on the empowerment perspective are effective [17].

There are several programmes available for the empowerment of people with a chronic disease. One of the most frequently used programmes is the Chronic Disease SelfManagement programme of Stanford University (CDSMP) developed by Lorig et al. in 2006 [18]. The CDSMP is an example of a lay-led health education programme aimed at helping participants develop a range of skills and confidence to deal more effectively with their chronic conditions [19]. A Cochrane review on the effectiveness of such self-management programmes by lay leaders [20] shows that these programmes can lead to short-term improvements in patients' confidence to manage their condition and perceptions of their own health. There were also significant improvements in cognitive symptom management of pain, disability, fatigue and depression [20]. The CDSMP has been shown to improve self-efficacy, self-management behaviour and health status, while reducing hospitalization and emergency visits [21-23]. The original CDSMP focuses on personal factors like lifestyle and disease-related factors like coping with symptoms of the disease. As this programme does not include work-related factors such as self-management behaviour at work, it doesn't fit entirely the needs of employees with a chronic disease.

In this study the method of intervention mapping (IM) [24] was used to adjust the original CDSMP for employees with a chronic somatic disease. The method of IM has been successfully applied earlier to develop a workplace intervention for sick listed employees with stress-related mental problems and musculoskeletal disorders [25,26] and a worksite physical intervention [27]. The focus of this paper is a detailed overview of how IM was used to develop a self-management programme for employees with a chronic somatic disease.

\section{Methods \\ Intervention mapping}

IM is a stepwise approach for theory and evidence based development and implementation of interventions. It comprises six steps, each leading to a product that guides the next step (see Figure 1) [24]. The present paper focuses mainly on the results of step one to four (creation of intervention) and also on the boundary conditions in order to carry out the intervention in the context of the evaluation study (step five and six).

\section{Step one: Needs assessment, literature review, and focus} groups

In step one a needs assessment is conducted starting with assessing the health problem. The health problem concerned has to be serious and must be related to behaviour. In order to detect modifiable factors, individual and environmental determinants of the risk behaviour are investigated (table 1). These investigations involve the application of behavioural determinants theories such as the theory of planned behaviour (1985) (which includes elements of Social cognitive theory of Bandura, 1977) and the protection motivation theory of Rogers (1975) $[24,28]$.

In the present study, firstly focus group interviews have been carried out with employees with RA, diabetes and hearing loss $(n=69)$ to explore the prerequisites for employees with a chronic disease to function at work [2931]. Secondly, the same question was explored through concept mapping with different health professionals (occupational health physicians, occupational health and specialist nurses, family doctors and specialists $\mathrm{n}=54$ ) [29-31]. Thirdly a systematic literature review was conducted to determine which prognostic factors are related to work disability in employees with a chronic somatic disease [32].

The needs assessment provided the information needed to be able to screen the content of the original CDSMP and compare this with the content needed for our target population.

\section{Step two: Identification of outcomes, performance objectives and change objectives}

Step two provides the foundation for the intervention by specifying who and what will change as a result of the intervention.

In order to analyze the determinants of self-management behaviour at work in this study the theory of planned behaviour (TPB) [33-35] was applied. The TPB postulates that intention, the most proximal determinant of behaviour, is determined by three independent constructs: attitude, social influence and perceived behav- 


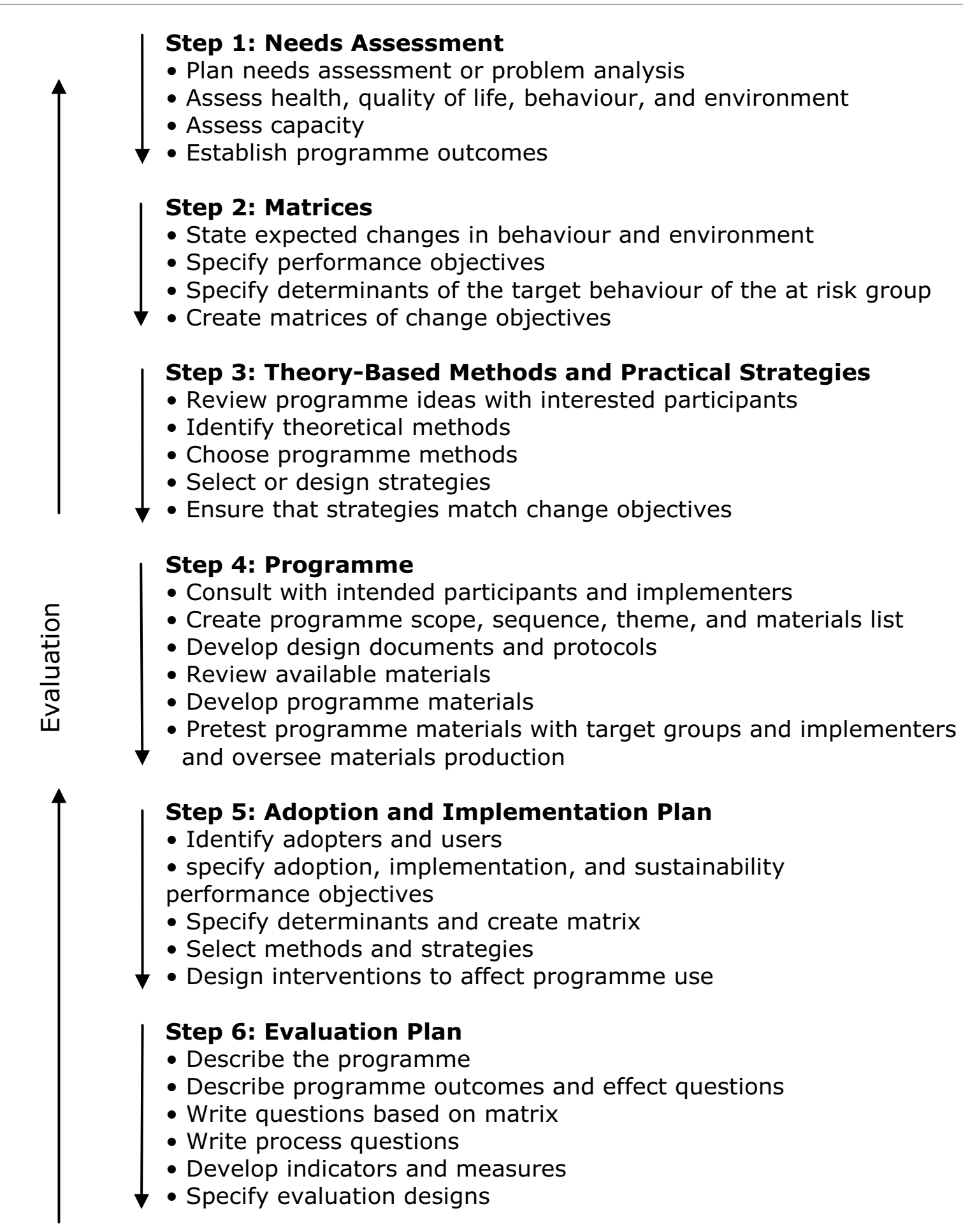

\section{Implementation}


Table 1: Identified important determinants of self-management behaviour at work.

\begin{tabular}{lll}
\hline Personal determinants & Socio-cultural determinants at work & Environmental determinants \\
\hline $\begin{array}{l}\text { Attitude towards asking help at work if needed } \\
\begin{array}{l}\text { Attitude towards coping with symptoms of } \\
\text { chronic disease }\end{array}\end{array}$ & Attitude of supervisor & Attitude of colleagues \\
$\begin{array}{l}\text { Self efficacy for asking for help } \\
\text { Self efficacy for coping with symptoms }\end{array}$ & Modelling behaviour of colleagues & Autonomy at work \\
Self efficacy for planning work & Relation with supervisor/colleagues & Work tasks/content \\
Awareness of risks of unhealthy lifestyle & Culture of company & Social relations at work \\
\hline
\end{tabular}

ioural control (self-efficacy) (Figure 2) [33-35]. In this step we defined the overall desired outcome of the adjusted intervention. The product of step two is a set of matrices of change objectives that combine performance objectives for personal and environmental determinants. Change objectives are the most immediate targets of an intervention [24].

\section{Step three: Selecting methods and practical strategies}

In step three theory-informed methods and practical strategies to change the behaviour of individuals are gathered. Change theories and theory-based change strategies (table 2) are then used to assess the changeability of the determinants. Examples of behavioural change theories are the goal-setting theory and social cognitive theory [24].
In this step of our study we have reviewed the literature on the CDSMP to be able to identify the effectiveness of methods and strategies used in the original CDSMP programme. For each determinant of behaviour appropriate methods were identified from the literature $[24,34]$. The methods and strategies of the original CDSMP were compared to the performance objectives for the intervention formulated in step two.

\section{Step four: Creating an organised programme plan}

The products in step four include a description of the scope and sequence of the components of the intervention.

For our study we compared the performance objectives of the original CDSMP to the performance objectives formulated for the adapted version of the CDSMP. The

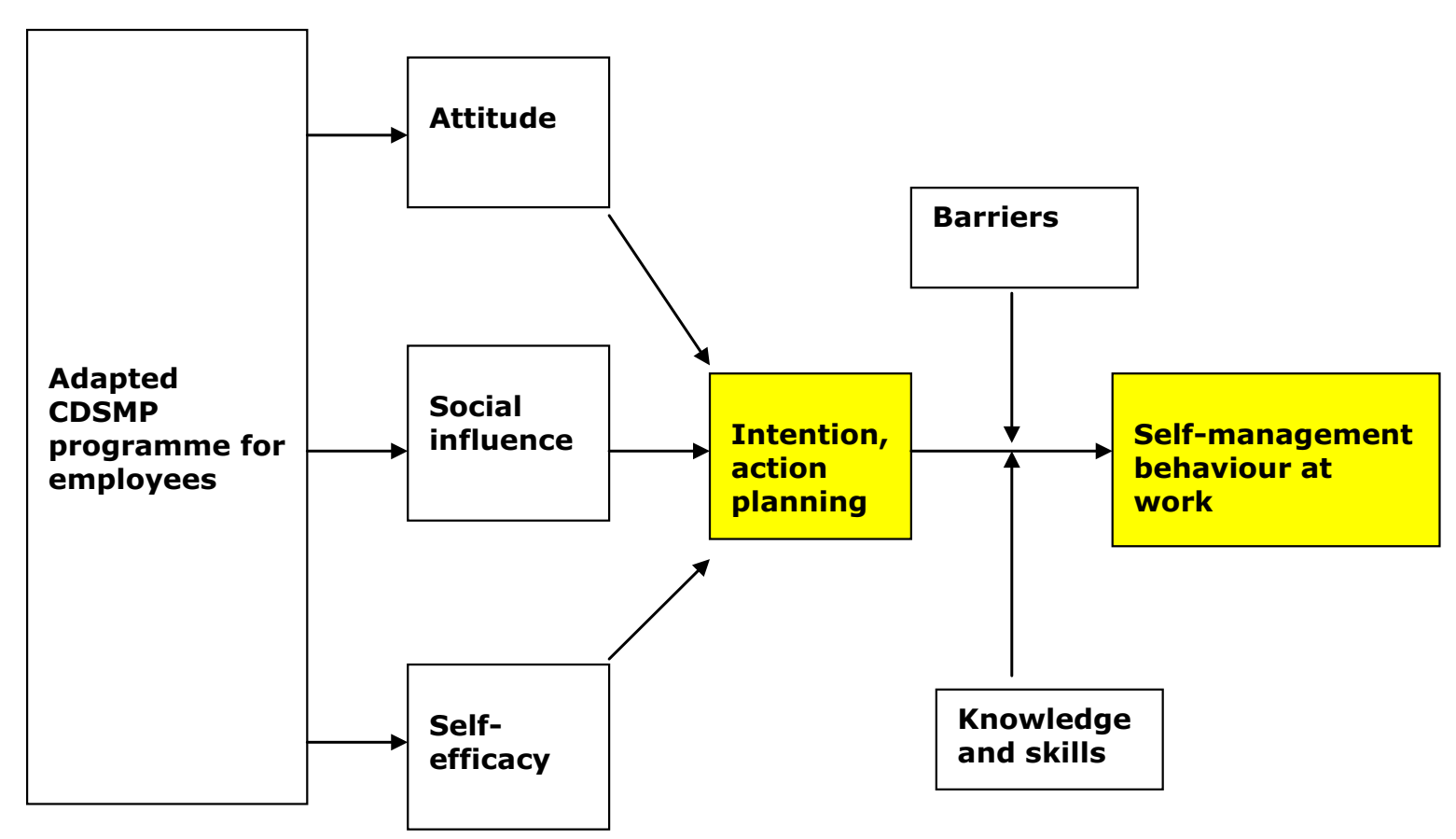

Figure 2 Determinants of behaviour model. Model representing how the adapted CDSMP programme can influence determinants of self-management behaviour at work, including the impact of barriers, knowledge and skills. 
Table 2: Methods for determinants translated in intervention.

\begin{tabular}{|c|c|c|}
\hline Determinant & Method & Strategies \\
\hline \multirow[t]{2}{*}{ Attitude } & Belief selection & $\begin{array}{l}\text { Through awareness exercises, based on brainstorm sessions and discussions, } \\
\text { participants learn to identify current beliefs on having a chronic disease, their } \\
\text { lifestyle and the problems encountered at work }\end{array}$ \\
\hline & Decisional balance & $\begin{array}{l}\text { Awareness exercises and brainstorm sessions also take place to identify } \\
\text { possible solutions }\end{array}$ \\
\hline \multirow[t]{2}{*}{ Self-efficacy } & Goal setting & $\begin{array}{l}\text { Participants formulate at the beginning of the course a long term and a short } \\
\text { term goal } \\
\text { Through weekly action plans participants can work on their self-efficacy and } \\
\text { their long term goal }\end{array}$ \\
\hline & Modelling & $\begin{array}{l}\text { Participants are (positively) influenced by the achievements of other } \\
\text { participants }\end{array}$ \\
\hline $\begin{array}{l}\text { Social influence and } \\
\text { support }\end{array}$ & $\begin{array}{l}\text { Modelling } \\
\text { Guided practice } \\
\text { Social comparison }\end{array}$ & $\begin{array}{l}\text { Through weekly action plans participants can mobilize social network and } \\
\text { social support at work }\end{array}$ \\
\hline \multirow[t]{2}{*}{ Knowledge } & $\begin{array}{l}\text { Information about the positive } \\
\text { effects of a healthy lifestyle }\end{array}$ & $\begin{array}{l}\text { Information in textbook } \\
\text { Presentations } \\
\text { Group sessions }\end{array}$ \\
\hline & $\begin{array}{l}\text { Information about determinants of } \\
\text { work disability for employees with a } \\
\text { chronic disease }\end{array}$ & $\begin{array}{l}\text { Information in textbook } \\
\text { Presentations } \\
\text { Group sessions }\end{array}$ \\
\hline \multirow[t]{3}{*}{$\begin{array}{l}\text { Risk perception (skills } \\
\text { for identifying high-risk } \\
\text { situations) }\end{array}$} & $\begin{array}{l}\text { Confrontation with risk of unhealthy } \\
\text { behaviour (lifestyle and behaviour at } \\
\text { the workplace) }\end{array}$ & $\begin{array}{l}\text { Through awareness exercises, based on brainstorm sessions and discussions, } \\
\text { participants learn to identify risks behaviours }\end{array}$ \\
\hline & Modelling & Course leader shares examples \\
\hline & $\begin{array}{l}\text { Skill training, with guided practice } \\
\text { and feedback }\end{array}$ & \\
\hline \multirow{2}{*}{$\begin{array}{l}\text { Skills for developing } \\
\text { coping, problem solving } \\
\text { and negotiation }\end{array}$} & Modelling & $\begin{array}{l}\text { Through awareness exercises based on brainstorm sessions and discussions } \\
\text { participants learn to identify barriers and how to handle them }\end{array}$ \\
\hline & $\begin{array}{l}\text { Skill training with guided practice } \\
\text { and feedback }\end{array}$ & Skills practice in role plays with feedback \\
\hline
\end{tabular}

objectives on lifestyle behaviour and coping with the disease were already included in the original CDSMP, as well as the aspect "communicating with health professionals". The theme "problems encountered at the workplace because of a chronic disease" was not included in the original CDSMP. Therefore we developed two additional sessions on what is needed to be able to work with a chronic disease and how to communicate with ones supervisor, colleagues and occupational health professionals about the problems encountered at work. In this step a plan was created for the adjusted intervention. Step five: Creation of an adoption and implementation plan The product of step five is a plan for accomplishing programme adoption and implementation.
In our study, several actions were taken to prepare the use of the programme in an evaluation study. Promotion material and a plan for the recruitment of participants for the training and the control group for the evaluation study were developed. It was ensured that facilitators received the correct training and instructions in order to carry out the training.

\section{Step six: Creating an evaluation plan}

In the final step of intervention mapping an evaluation plan

In this step we have developed a plan for the quantitative and qualitative evaluation of our evaluation study. The results of the evaluation study will be presented and discussed elsewhere when available. 


\section{Results}

\section{Step one: Needs assessment} Focus groups

Three focus groups with employees with RA, diabetes and hearing loss (total $n=69$ ) were held to explore the prerequisites for employees with a chronic disease to function at work [28-30]. The same question was explored through concept mapping with different health professionals (occupational health physicians, occupational health and specialist nurses, family doctors and specialists; $n=54$ ). For the employees with RA, the support of management was the most important, followed by self-acceptance, self-efficacy, and professional advice on how to cope at work. For employees with diabetes mellitus, self-acceptance, self-care, and support from management, colleagues and health professionals were rated to be the most important. For the employees with hearing loss, to have knowledge of hearing aids was the most important, followed by communication strategies, the ability to cope with the disease, to be assertive and the support of occupational physicians [29]. According to the health professionals [30,31], employees with a chronic disease need self-management skills to manage their disease (for example to accept their illness, to communicate about it with others and to feel confident enough to work). A supportive family and work-environment was also perceived as an enabling condition for work. Furthermore support from health professionals and a balance between workload and capacities were considered to be important. The findings of the focus groups also suggest that occupational health interventions should pay attention to personal factors, disease related factors and psychosocial factors at the workplace.

\section{Literature review}

Different risk factors for work (dis)ability have been identified in the literature for employees with a chronic somatic disease like RA, Ischemic heart disease, asthma or COPD: a physically demanding job, precision work, lack of control over the pace and activities of work, lack of support by supervisors, managers and colleagues and complexity of work. Disease related factors such as pain, fatigue and poor functional status are important factors for leaving the workplace [32,36-39]. Informing colleagues about having the disease seems to be positively associated with continuing to work as well as adjusting job demands and behavioural coping at work [40]. Systematic reviews on prognostic factors for work-(dis)ability support the consideration that many personal, disease-related and work-related factors are common for certain chronic physical diseases [32,41]. The findings of the literature review suggest that occupational health interventions should pay attention to personal factors, disease related factors and psychosocial factors at the workplace.
Factors such as the competence to ask for support, to adjust working demands, to accept the disease and to cope with the disease at work can probably be influenced by a self-management programme $[11,42]$. Based on the findings of the focus groups and literature review we decided to screen the content of the original CDSMP and compare the content to the needs of our target population. The original CDSMP focuses on personal factors like lifestyle, self-efficacy and skills to communicate about the disease. The original CDSMP also focuses on disease-related factors like coping with symptoms of the disease. The results of the needs assessment give insight that the original CDSMP already covers many aspects which are important for employees with a chronic disease. The only aspect which is not incorporated in the original CDSMP is work-related factors such as self-management behaviour at work. We decided therefore to adjust the original CDSMP to fit the needs of employees with a chronic disease. The next step was to identify and formulate personal, socio-cultural and environmental determinants for self-management behaviour at work (Table 1). The personal determinants are possibly directly influenced by the course and can possibly indirectly affect the socio-cultural and environmental determinants at work.

\section{Step two: Matrices of change objectives}

Based on the needs assessment, the overall behavioural outcome was defined as "Self-management behaviour at work".

The aim of the CDSMP for employees with a chronic somatic disease is to obtain self-management behaviour at work. Self-management behaviour at work has been operationalized as follows:

1 ), To be able to ask help from colleagues and supervisor when needed (ask for facilities at work, ask for change in job demands).

2), To be able to cope with symptoms as pain, fatigue, breathing problems and emotional ups and downs at work and carry out a healthy lifestyle.

3 ), To be able to re-organize work according to disease (to plan work according to disease, to take pauses when needed and to say no when needed).

Furthermore the main determinants of behaviour change according to the theory of planned behaviour [33]; (1) the attitude, (2) social influence and (3) perceived behavioural control to behaviour (Figure 2) have been operationalized as follows:

1. Attitude: A person's attitude consists of the perceived cognitive and emotional advantages and disadvantages of the behaviour, including beliefs that a specific type of behaviour can be completed. How positive is the person about the capability to ask support from colleagues and supervisor at work, to cope with symptoms as pain, 
fatigue, breathing problems and emotional ups and downs, to carry out a healthy lifestyle and to reorganize work according to the disease.

2. Social influence: (perception of) social support at work and acquiring social support at work. Social influences consist of the perception of others carrying out this type of behaviour (social modelling), the norms that people have with respect to these behaviours (social norms) and the support that they perceive from others in carrying out a particular type of behaviour.

3. Self-efficacy: how confident is the person on his ability to ask for support when needed at work, to cope with symptoms at work, to carry out a healthy lifestyle and to reorganize work according to the disease. Self-efficacy refers to a person's perception of his capability to carry out the type of behaviour.

The intervention is aimed to influence all three determinants of behaviour but specially the self-efficacy at work. According to the theory of planned behaviour, behaviour is best predicted by the intention of the person to perform that behaviour [24]. Recent findings support that action planning is a better predictor of behaviour than the intention [43]. Interventions are proven to be more effective if they focus on improving participants' action planning activity, their self-efficacy and self regulatory capabilities rather than focusing on intentionenhancing risk perceptions $[44,45]$.

\section{Step three: Theory-based methods and practical strategies}

There is systematic evidence available on effective methods to stimulate self-management behaviour at work. A systematic review on the effectiveness of empowerment interventions at the workplace [16] showed that most existing interventions have the objective:

- to increase knowledge (about the disorder and its consequences, legal rights and work accommodations)

- to gain a clear understanding of work-related problems or work barriers

- to increase feelings of control (general control or perceived self-efficacy in the process to request work accommodations)

- to develop skills (coping skills and social competences)

- to increase activities aimed at work accommodations

The objectives of existing empowerment interventions at the workplace focus primarily on acquiring skills and behaviour change. The CDSMP programme for employees focuses on skills and behaviour change by improving participants' action planning activity, self-efficacy and self regulatory capabilities as well as influencing their intention and risk perceptions. In table 2 the different techniques used in the course to influence the determinants of behaviour are shown.
The techniques for behavioural change used in the selfmanagement programme to influence the determinants are: consciousness raising (belief selection, decisional balance), risk perception, positive reframing, self-re-evaluation, enhancing self-efficacy and social support, skill mastery, reinterpretation of symptoms, goal setting, social comparison, modelling, and persuasion of positive outcomes $[24,46,47]$.

The attitude of the participants is influenced by awareness exercises to raise their consciousness on situations at the workplace which are difficult to deal with a chronic disease. Participants are encouraged to formulate possible solutions. Self-management behaviour is also influenced by the attitude and actions of the other participants.

The social support at work is influenced by encouraging employees to talk about the course and action plans with colleagues and supervisor.

The self-efficacy is influenced by social comparison $[48,49]$ through success stories of other participants. Through goal setting (action plans) the participants can focus on working on their self-efficacy, based on the level of the participant. Goal setting leads to better performance because people with explicit goals exert themselves to a greater extent and persevere in their tasks [50,51]. A goal should be behaviourally SMART formulated (specific, measurable, attainable, realistic and timely) and should be stated in terms of behaviour (ask for help at work) instead of health outcomes, e.g. oriented on more social support from colleagues [47,52]. Participants formulate weekly a goal with regard to self-management behaviour, for example, to exercise, to practice time management at work or to take pauses at work, which they intend to accomplish during the following week. After formulating the plan, the participant has to state how confident he is that he will execute the action plan. If the level of confidence is below 7 (on a 1-10 scale), the participant is coached in re-formulating his action plan by the course leaders until a higher level of confidence is achieved [47]. During the next session, the participants report whether or not they have accomplished their action plan, and to give an account if any possible problems that might have arisen are solved. This feedback is an integral part of skills mastery.

\section{Step four: programme}

In step four, we created a modified plan for the programme taking into account the budget and resources for the programme materials. The course consists of six sessions of each two and a half hour, this conform the programme plan of the original CDSMP. An overview of the adapted CDSMP for employees is shown in table 3. For this target group, two extra sessions have been developed based on the model of work load and work capacity [53] 
by using the methods of the original CDSMP (e.g. consciousness raising, risk perception, positive reframing, skill mastery, goal setting). Furthermore the original CDSMP topics were enriched with new topics on the work situation of employees with a chronic disease.

The programme plan has been produced conform the boundary limits of the original CDSMP. The original programme is intended for (lay)-trainers who have completed the Master trainers programme at Stanford University. The original CDSMP design is a high feasible low-cost programme which can practically be implemented in every setting. The only boundary limits for the programme are: two trainers (one must be a master trainer at Stanford University and the other trainer must have received a leaders training by the master trainer), inset time approximately 5 hours per session (training plus preparation time) and an accessible accommodation (room) for minimal 15 participants and facilities like access to beverages, toilet access and an elevator.

\section{Step five: Adoption and implementation plan}

The results of step five were a well defined set of inclusion criteria for the participants, a plan for the recruitment of participants for the training in the context of the evaluation study, a plan to train the facilitators and a Dutch manual for the participants and the facilitators [54].

The inclusion criteria to select participants for the course were: employees with a diagnosed chronic physical disease, with a paid job at the moment of the course, who encounter problems at work because of their disease and who were motivated to follow the course. The exclusion criteria were: Employees with predominant psychiatric conditions, more than three months totally absent from work and fully work-disabled.

Participants for the course were recruited through the departments of Human Resource Management from companies, general practitioners and occupational health services in the region of Arnhem and Nijmegen in the Netherlands. An information letter and leaflet of the course were sent to 82 companies, 88 general practitioners and 10 occupational health services in both municipalities. Also several advertisements have been placed in regional newspapers. Participants were requested to contact the researcher (SD) by telephone or email for more information or to apply for the programme. Before being admitted to the programme participants were screened on the inclusion criteria by telephone. After registration the participants received a written confirmation, the informed consent form, the questionnaire and information about the procedures. All participants who have been admitted to the programme by telephone were randomized to either the control group or the intervention group. The control group consisted of care as usual and the intervention group consisted of care as usual plus the self-management programme. Both groups were followed for eight months.

Participants in the control group who were followed for eight months and had returned all the questionnaires in the control group and still wanted to apply for the selfmanagement programme were allowed to follow the programme. The data of these participants has been included in the analysis of the control group and excluded from the analysis of the intervention group in the evaluation study.

We modified the course handbook for the participants and translated the manual in Dutch under the title "Werken met een chronische aandoening" (Working with a chronic disease) [54]. We also produced a manual for the facilitors including step by step instructions on how to implement the intervention. The course must be facilitated by two moderators. One of them is to be trained at the University of Stanford to be a master trainer of the CDSMP.

\section{Step six: Evaluation Plan}

The result of step six was an evaluation plan for the evaluation study. The study design and operationalization of the evaluation study have been approved by the Medical Ethics Committee of the Radboud University Nijmegen and are registered in the Dutch Trial Register as (NTR 1737).

The effect-evaluation consists of a randomized controlled trial $(\mathrm{n}=104)$ with eight months follow-up and a qualitative evaluation among the participants of two training groups $(\mathrm{n}=15)$. In this study, we wanted to include at least 35 patients in the RCT in each group in order to be able to detect a statistically significant difference on the outcome SF-12 and coping with symptoms (Stanford questionnaire coping with symptoms). This sample size was based on a intervention study, in which 35 patients in each group were needed in order to achieve an effect-size of 0.8 on the SF- 12 with a power of $80 \%$ and an alpha at $<5 \%$ (two tailed) [55,56]. Assuming a drop-out rate of $20 \%$ during the trial a total of 104 participants have to be included in the randomization process.

Our primary analysis was by intention to treat and participants were at random selected for the control group or the intervention group. After selection they were informed about the intervention and control conditions. The control group received care as usual and the intervention group consisted of care as usual plus the selfmanagement programme. A questionnaire has been developed including primary and secondary outcome measures. The primary outcome measures of the effect evaluation are self-efficacy at work, the intention to communicate with supervisor and occupational physician, work pleasure (VBBA) [57] and work productivity (WAI) [58], coping with symptoms like pain and fatigue (Stan- 
Table 3: Content of the self-management programme for employees with a chronic somatic disease.

\begin{tabular}{lll}
\hline Timing & Lesson & Topics \\
\hline Week 1 & $\begin{array}{l}\text { Introduction } \\
\text { Importance of physical exercise }\end{array}$ & - Overview of the course \\
& - Objectives of the course \\
& - Objectives of the participants \\
& - Inventory of problems encountered at work by the chronic disease \\
& - Introduction to cope with symptoms by using guided imagery \\
& - The importance of physical exercise for people with a chronic disease \\
& - Introduction to making action plans
\end{tabular}

\begin{tabular}{ll}
\hline Week 2 Coping with pain, fatigue and stress at work & - Symptoms that interfere with the ability to work \\
& - Situations causing stress, pain or fatigue (at work) \\
& - Solutions to deal with stress, pain or fatigue (at work) \\
& - Breathing exercises \\
& - Introduction to cognitive symptom management
\end{tabular}

\begin{tabular}{lll}
\hline Week 3 Importance of healthy nutrition/Problems encountered at & - Introduction to healthy nutrition \\
work & & - The importance of healthy nutrition for people with a chronic disease \\
& - Introduction to working with a chronic disease \\
& - Introduction to the model of work load and work capacity \\
& - Solutions at the workplace \\
\hline Week 4 Communication techniques at the workplace & - Communication techniques \\
& $\begin{array}{l}\text { - How to communicate with supervisor and colleagues about the } \\
\text { problems encountered at work } \\
\end{array}$ & $\begin{array}{l}\text { - How to communicate with supervisor and colleagues about possible } \\
\text { solutions at work } \\
\text { - How to communicate with family and friends about the problems and } \\
\text { possible solutions to combine work and home }\end{array}$
\end{tabular}

Week 5 Working together with occupational health professionals

Week 6 Plans for the future
- Working together with occupational health professionals and HRM advisors at work

- What has been accomplished the past six weeks?

- What have we learned in the course?

- Formulating long-term plans

ford questionnaire coping with symptoms) and Quality of life and general health (SF-12) [59]. For the purpose of measuring self-efficacy at work, a self-efficacy at work instrument has been developed. The content of this questionnaire has been developed with the information obtained through the focus groups with professionals and patients.

The qualitative evaluation study consists of semi-structured interviews with fifteen participants. The participants were interviewed two times, at the beginning and after the course. Secondly, all brainstorm topics generated during the course related to the problems encountered at work and the solutions will be analyzed using content analysis.

The results of the RCT and the qualitative evaluation will be presented, when available, in separate articles.

\section{Discussion}

We aimed to describe the development and content of a theory- and practise-based prevention programme for 
employees with a chronic somatic disease. Intervention mapping (IM) was used to develop an intervention based on the Chronic Disease Self-Management programme (CDSMP). Following each IM step carefully, made it possible to adapt the existing CDSMP programme to the needs of employees with a chronic disease. A systematic approach for the development is needed in order to build a theory-based intervention that fits the needs of a specific population [24,33,34]. At this stage it is not possible to draw conclusions about the effectiveness of the programme and the best context to diffuse the programme.

To our knowledge this is the first study, which has applied IM for the development of an occupational health intervention for employees with a chronic somatic disease. IM has been proven to be a helpful tool to screen existing interventions like the original CDSMP of Stanford University and to tailor the intervention for a specific population. Although IM provides a useful checklist to take the right steps in developing an intervention, it does include the risk to be a time-consuming process according to the IM textbook, especially for the development of totally new interventions. In our study, we experienced that IM is a useful checklist to relatively quickly tailor an existing intervention that has already been proven to be effective in helping participants to cope with their disease in general. The adapted intervention plan was completed in three months (analyses of step 1 to step 4). IM can be used in occupational health to screen and adjust existing interventions for different target groups $[25,26]$.

A possible strength of the IM approach is the use of theories and methods for behaviour change like for instance the theory of planned behaviour which includes elements of the social-cognitive theory and goal-setting theory; these have been chosen in our study to influence the determinants of behaviour [24]. Recent insights in occupational health support the use of such conceptual models when developing evidence-based occupational health interventions [14]. Conceptual models are needed to construct an intervention tailored for the needs of a specific population and avoid trial and error procedures which may cost even more time and resources in the long-run.

Another possible strength of the programme is the generic character of the training. The information from the needs-assessment supports the idea that the determinants for work-ability are the same for different chronic somatic diseases. The generic character of the programme contributes to the feasibility of the programme in different contextual settings.

A difficulty might be that the theoretical knowledge and the experience with techniques that can be applied to influence the determinants of behaviour are insufficiently available in the field of occupational health care to apply
IM. Another point of concern is the time available in health care settings to construct interventions according to the IM protocol. Wolfers et al. 2007 propose therefore a flexible and more pragmatic use of IM while still guaranteeing the quality of a systematic approach [60].

A possible weakness of our study is that the vision of employers has not been taken into account in the development of the intervention. The intervention has been constructed based on evidence found in the literature and on the vision of employees and health professionals. Probably, employers can mention relevant points not addressed yet during the training. Another point of discussion is whether a self-management programme for the employee is sufficient to facilitate the work-ability of employees with a chronic disease or whether the physical and social working environment should also be the object of an intervention.

The validity of the programme in different contextual settings like a company or occupational health service or in different countries is not studied yet. However, the content of the programme is to our knowledge transferable to different contextual settings under the condition that the target population and objectives of the contextual setting are the same as the target population and objectives of the present programme. Nevertheless we recommend screening the programme according to the IM checklist (figure 1) before using the programme for a different target population.

Another point of concern is that the training is not tailored for participants according to a stage of behavioural change and one specific behavioural goal. The course has been build to suit the needs of people in different stages of behavioural change and participants work on different behaviour goals. Probably this can cause a problem when evaluating the effects of the training on a specific behaviour.

To date, IM has been mainly used as a tool for the planning and development of health promotion interventions to suit the needs of a specific target population. Recently, promising results were shown for the use of IM in occupational health care research $[25,26]$. This study shows that IM can also be used to adjust existing generic programmes for specific working populations.

An article describing the methods and results of the $\mathrm{RCT}$ and recommendations for the diffusion of the programme will be submitted in the near future. An article on the qualitative evaluation is already submitted.

\section{Conclusion}

In this study the original Chronic Disease Self-management programme has been tailored for employees with a chronic disease by adding new elements. The method of Intervention Mapping provided the tools needed to do this systematically. IM seems to be a proper method for 
the systematic development (or adjustment) of interventions in (occupational) health care.

\section{Competing interests}

The authors declare that they have no competing interests.

\section{Authors' contributions}

SD carried out the study, participated in the design of the study, performed the analyses and drafted the manuscript. YH and JE participated in the design of the study and helped to draft the manuscript. JG and FD participated in the design of the study, discussed interpretation of results and helped draft the manuscript. All authors read and approved the final manuscript.

\section{Acknowledgements}

This study was financially supported by the HAN University of Applied Sciences in the Netherlands. The authors wish to acknowledge the contribution of Tjeerd de Jong, Frank Stöteler and Velibor Peters, HAN University of Applied Sciences and Prof. Dr Kate Lorig of Stanford University.

\section{Author Details}

ISeneca, Expertise Centre for Sports, Work and Health, HAN University of Applied Sciences, Nijmegen, The Netherlands, ${ }^{2}$ Department of Primary and Community Health, Radboud University, Nijmegen Medical Centre, The Netherlands, ${ }^{3}$ Faculty of Health and Social Studies, HAN University of Applied Sciences, Nijmegen, The Netherlands, ${ }^{4}$ Faculty of Health and Social Studies, HAN University of Applied Sciences, The Netherlands and ${ }^{5}$ Coronel Institute of Occupational Health, Academic Medical Center, University of Amsterdam, The Netherlands

Received: 23 September 2009 Accepted: 21 June 2010

Published: 21 June 2010

\section{References}

1. Tu HT, Cohen GR: Financial and health burdens of chronic conditions grow. Results from the community tracking study. Center for Studying health system change 2009.

2. Bhattacharya J, Choudhry K, Lakdawalla D: Chronic disease and severe disability among working-age populations. Med Care 2008, 46(1):92-100

3. Blokstra A, Baan CA, Boshuizen HC, Feenstra TL, Hoogenveen RT, Picavet HS: Impact of the ageing population on burden of disease: projections of chronic disease prevalence for 2005-2025. National Institute for Public Health and Environment 2007.

4. Van den Brink-Muinen A, Spreeuwenberg P, Rijken PM: National Panel of the chronically ill and Disabled (NPCG). Netherlands Institute for Health Services Research 2007.

5. Chorus AM, Miedema HS, Boonen A, Van Der Linden S: Quality of life and work in patients with rheumatoid arthritis and ankylosing spondylitis of working age. Ann Rheum Dis 2003, 62(12):1178-84.

6. Verstappen SMM, Boonen A, Bijlsma JWJ, Buskens E, Verkleij H, Schenk Y, Albada-Kuipers GA van, Hofman DM, Jacobs JWG: Working status among Dutch patients with rheumatoid arthritis: work disability and working conditions. Rheumatol 2005, 44:202-206.

7. Blanc PD, Yen $\mathrm{H}$, Chen $\mathrm{H}$, Katz PP, Earnest $\mathrm{G}$, Balmes J: Area-level socioeconomic status and health status among adults with asthma and rhinitis. Eur Respir $J$ 2006, 27(1):85-94.

8. Young A, Dixey J, Kulinskaya E, Cox N, Davies P, Devlin J: Which patients stop working because of rheumatoid arthritis?: results of five years' follow up in 732 patients from the Early RA Study (ERAS). Ann Rheum Dis 2002, 61(4):335-40.

9. Rijken M, van Kerkhof J, Dekker FG, Schellevis : Comorbidity of chronic diseases: effects of disease pairs on physical and mental functioning. Quality of Life Research 2005, 14:45-55.

10. The Netherlands Working Conditions Survey. TNO Work and Employment 2008

11. Kosciulek JF: Empowering People with Disabilities. Through Vocational Rehabilitation Counseling. American Rehabilitation 2004:40-47.

12. Barlow J, Wright C, Sheasby J, Turner A, Hainsworth J: Self-management approaches for people with chronic conditions: A review. Patient Education and Counseling 2002, 48:177-187.
13. de Vos K: Financial incentives for retaining or taking workers: a literature review. CentER Applied Research 2004.

14. Verbeek J, Husman K, van Dijk F, Jauhiainen M, Pasternack I, Vainio H: Building an evidence base for occupational health interventions. Scand J Work Environ Health 2004, 30(2):164-70.

15. Hétu R, Getty L: Development of a rehabilitation programme for people affected with occupational hearing loss. 1. A new paradigm. Audiology 1991, 30(6):305-16.

16. Allaire $\mathrm{SH}$, Anderson JJ, Meenan R: Reducing work disability associated with rheumatoid arthritis: identification of additional risk factors and persons likely to benefit from intervention. Arthritis Care Res 1996, 9(5):349-57.

17. Varekamp I, Verbeek JH, van Dijk FJ: How can we help employees with chronic diseases to stay at work? A review of interventions aimed at job retention and based on an empowerment perspective. Int Arch Occup Environ Health 2006, 80(2):87-97.

18. Lorig K, Holman HR, Sobel D, Laurent D, González V, Minor M: Living a healthy life with chronic conditions. Boulder CO: Bull Publishing; 2006

19. Lorig KR, Holman $\mathrm{H}$ : Self-management education: history, definition, outcomes, and mechanisms. Ann Behav Med 2003, 26(1):1-7

20. Foster G, Taylor SJ, Eldridge SE, Ramsay J, Griffiths CJ: Self-management education programmemes by lay leaders for people with chronic conditions. Cochrane Database Syst Rev 2007.

21. Lorig KR, Ritter P, Stewart AL, Sobel DS, Brown BW Jr, Bandura A, Gonzalez VM, Laurent DD, Holman HR: Chronic disease self-management programme: 2-year health status and health care utilization outcomes. Med Care 2001, 39(11):1217-23.

22. Lorig KR, Sobel DS, Ritter PL, Laurent D, Hobbs M: Effect of a selfmanagement programme on patients with chronic disease. EffClin Pract 2001, 6:256-62.

23. Goeppinger J, Arthur M, Baglioni AJ: A re-examination of the effectiveness of self-care education for persons with arthritis. Arthritis and Rheumatism 1989, 32:706-16.

24. Bartholomew L, Parcel G, Kok G, Gottlieb N: Planning health promotion programmes. Jossey-Bass; 2006.

25. van Oostrom SH, Anema JR, Terluin B, Venema A, de Vet HC, van Mechelen W: Development of a workplace intervention for sick-listed employees with stress-related mental disorders: Intervention Mapping as a useful tool. BMC Health Serv Res 2007, 15(7):127.

26. Vermeulen SJ, Anema JR, Schellart AJ, van Mechelen W, van der Beek AJ: Intervention mapping for development of a participatory return-towork intervention for temporary agency workers and unemployed workers sick-listed due to musculoskeletal disorders. BMC Public Health 2009, I 2(9):216.

27. McEachan RR, Lawton RJ, Jackson C, Conner M, Lunt J: Evidence, theory and context: using intervention mapping to develop a worksite physical activity intervention. BMC Public Health 2008, 22(8):326.

28. Kwak L, Kremers SP, Werkman A, Visscher TL, van Baak MA, Brug J: The NHF-NRG In Balance-project: the application of Intervention Mapping in the development, implementation and evaluation of weight gain prevention at the worksite. Obes Rev 2007, 8(4):347-61.

29. Detaille SI, Haafkens JA, van Dijk FJ: What employees with rheumatoid arthritis, diabetes mellitus and hearing loss need to cope at work. Scand J Work Environ Health 2003, 29(2):134-42.

30. Detaille SI, Haafkens JA, Hoekstra JB, van Dijk FJ: What employees with diabetes mellitus need to cope at work: views of employees and health professionals. Patient Educ Couns 2006, 64(1-3):183-90.

31. Varekamp I, Haafkens JA, Detaille SI, Tak PP, van Dijk FJ: Preventing work disability among employees with rheumatoid arthritis: what medical professionals can learn from the patients' perspective. Arthritis Rheum 2005, 15; 53(6):965-72.

32. Detaille SI, Heerkens YF, Engels JA, van der Gulden JW, van Dijk FJ: Common prognostic factors of work disability among employees with a chronic somatic disease: a systematic review of cohort studies. Scand J Work Environ Health 2009, 35(4):261-81.

33. Fishbein M, Ajzen I: Belief, Attitude, Intention and Behaviour: An Introduction to Theory and Research. Addison-Wesley; 1975.

34. Green LW, Kreuter MW: Health Promotion Planning: an educational and environmental approach. Mountain view, CA: Mayfield; 1999.

35. Brug J, Schaalma H, Kok G, Meertens RM, Molen HT, van der : Gezondheidsvoorlichting en gedragsverandering. Een planmatige aanpak. Van Gorcum 2008. 
36. Reisine S, Fifield J, Walsh SJ, Feinn R: Factors associated with continued employment among patients with rheumatoid arthritis: a survival model. J Rheumatol 2001, 28(11):2400-8.

37. Yelin E, Katz P, Balmes J, Trupin L, Earnest G, Eisner M: Work life of persons with asthma, rhinitis, and COPD: a study using a national, populationbased sample. J Occup Med Toxicol 2006, 2(1):2.

38. Mancuso CA, Paget SA, Charlson ME: Adaptations made by rheumatoid arthritis patients to continue working: a pilot study of workplace challenges and successful adaptations. Arthritis Care Res 2000, 13:89-99.

39. Puolakka K, Kautiainen H, Möttönen T, Hannonen P, Hakala M, Korpela M: Predictors of productivity loss in early rheumatoid arthritis: a 5 year follow up study. Ann Rheum Dis 2005, 64(1):130

40. Chorus AM, Miedema HS, Boonen A, Van Der Linden S: Quality of life and work in patients with rheumatoid arthritis and ankylosing spondylitis of working age. Ann Rheum Dis 2003, 62(12):1178-84.

41. Slebus FG, Kuijer PP, Willems HJ, Sluiter JK, Frings-Dresen MH: Prognostic factors for work ability in sicklisted employees with chronic diseases. Occup Environ Med 2007 in press.

42. Varekamp I, Heutink A, Landman S, Koning CE, de Vries G, van Dijk FJ: Facilitating Empowerment in Employees with Chronic Disease: Qualitative Analysis of the Process of Change. J Occup Rehabil 2009:7.

43. Sniehotta FF, Scholz U, Schwarzer R, Fuhrmann B, Kiwus U, Völler H: Longterm effects of two psychological interventions on physical exercise and self-regulation following coronary rehabilitation. Int J Behav Med 2005, 12(4):244-55.

44. Lippke S, Ziegelmann JP, Schwarzer R: Behavioral intentions and action plans promote physical exercise: A longitudinal study with orthopedic rehabilitation patients. Journal of Sport \& Exercise Psychology 2004, 26:470-483.

45. Bodenheimer T, Lorig K, Holman H, Grumbach K: Patient selfmanagement of chronic disease in primary care. JAMA 2002, 20; 288(19):2469-75.

46. Lorig K: Self-management education: More than a nice extra. Medical Care 2003, 41(6):699-701.

47. Lorig K: Action planning: a call to action. J Am Board Fam Med 2006, 19(3):324-5

48. Suls J, Wheeler L: Selective history of classic and neo-social comparison theory. Handbook of Social Comparison. Kluwer Academic Plenum Publishers; 2000.

49. Festinger L: A theory of social comparison processes. Human Relations 1954, 7:117-40.

50. Locke EA, Latham GP: Building a practically useful theory of goal setting and task motivation: A 35-year odyssey. American Psychologist 2002, 57:701-717.

51. Latham GP, Locke EA, Fassina NE: The high performance cycle: Standing the test of time. In S. Sonnentag (Ed.), The psychological management of individual performance. A handbook in the psychology of management in organizations. Wiley; 2002:201-228.

52. Strecher VJ, Seijts GH, Kok GJ, Latham GP, Glasgow R, DeVellis B, Meertens RM, Bulger DW: Goal setting as a strategy for health behavior change. Health Educ Q 1995, 22(2):190-200.

53. Dijk van FJ, Dormolen van M, Kompier MA, Meyman T: Revaluation of the model of work load and work capacity. Tijdschr Soc Gezondheidsz 1990, 68(1):3-10.

54. Detaille SI, Heerkens YF, Engels JA, van der Gulden JW, van Dijk FJ: Working with a chronic disease, Dutch translation CDSMP. HAN University of Applied Sciences 2006.

55. Holman R, Glas CA, de Haan RJ: Power analysis in randomized clinical trials based on item response theory. Control Clin Trials 2003, 24(4):390-410.

56. Stulemeijer M, de Jong LW, Fiselier TJ, Hoogveld SW, Bleijenberg G: Cognitive behaviour therapy for adolescents with chronic fatigue syndrome: randomised controlled trial. BMJ 2005, 1;330(7481):14.

57. Houkes I, Janssen PP, de Jonge J, Bakker AB: Personality, work characteristics, and employee well-being: a longitudinal analysis of additive and moderating effects. J Occup Health Psychol 2003, 8(1):20-38.

58. IImarinen J: The Work Ability Index (WAI). Occup Med 2007, 57:160

59. Mols F, Pelle AJ, Kupper N: Normative data of the SF-12 health survey with validation using postmyocardial infarction patients in the Dutch population. Qual Life Res 2009, 18(4):403-14
60. Wolfers ME, van den Hoek C, Brug J, de Zwart O: Using Intervention Mapping to develop a programmeme to prevent sexually transmittable infections, including HIV, among heterosexual migrant men. BMC Public Health 2007, 5(7):141

\section{Pre-publication history}

The pre-publication history for this paper can be accessed here: http://www.biomedcentral.com/1471-2458/10/353/prepub

doi: $10.1186 / 1471-2458-10-353$

Cite this article as: Detaille et al., Using intervention mapping (IM) to develop a self-management programme for employees with a chronic disease in the Netherlands BMC Public Health 2010, 10:353

\section{Submit your next manuscript to BioMed Central and take full advantage of:}

- Convenient online submission

- Thorough peer review

- No space constraints or color figure charges

- Immediate publication on acceptance

- Inclusion in PubMed, CAS, Scopus and Google Scholar

- Research which is freely available for redistribution

Submit your manuscript at www.biomedcentral.com/submit
C) Biomed Central 